\title{
HIERARQUIA DAS ARTES
}

Hierarchy of the arts

\section{Erinaldo Sales}

Doutor pela FAU/ UnB na linha de Estética e Semiótica, licenciado em Letras, mestre em Teoria Literária pela Universidade de Brasília, professor na Secretaria de Educação do Distrito Federal.

\section{Resumo}

Este trabalho analisa a situação da arquitetura e da poesia no âmbito das chamadas belas-artes a partir das considerações de três filósofos alemães: Immanuel Kant, Georg W. F. Hegel e Arthur Schopenhauer. Buscase uma tentativa de entendimento de o porquê a poesia estar sempre numa posição elevada dentro da hierarquia do sistema das artes e a arquitetura figurar sempre na base dessa hierarquia.

Palavras-chave: Sistema das artes; arquitetura; poesia; belas-artes; filosofia.

\section{Abstract}

This work analyzes the situation of architecture and poetry in the context of the fine arts from the considerations of three German philosophers: Immanuel Kant, Georg W. Hegel and Arthur Schopenhauer. An attempt is made to understand why poetry is always in an elevated position within the hierarchy of the art system and architecture is always at the base of this hierarchy.

Keywords: System of the arts; architecture; poetry; fine arts, philosophy. 


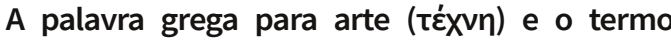
equivalente latino (ars) não são relacionados diretamente ao que é chamado nos dias de hoje de belas-artes. Aqueles dois termos se referiam a todo tipo de atividade humana, desde $o$ artesanato at as ciências. Os antigos compreendiam a arte como o que podia ser ensinado e aprendido.

Em se tomando a perspectiva progressiva da história, ou, em outros termos, encontramos por volta do século V a.C uma das primeiras distinções de arte, com Alcidamente, enfocando certos objetos que serviam unicamente ao prazer. Tendo sempre algumas artes (technés) voltadas para o prazer e para a beleza e outras para o uso prático, essa divisão vai permanecer em todo o progresso da história e dos estudos das artes.

Dentro desse aspecto duplo da arte, temos a oposição entre atividades voltadas para o trabalho manual e aqueles trabalhos que destacam um aspecto elevado do fazer, embora, em geral, essas atividades englobassem tanto a construção de navios, de armas, de estradas, bem como uma escultura, uma pintura ou mesmo um texto poético. Isso resultou numa separação inicial entre artes vulgares e humildes e artes recreativas, que tinham por finalidade apenas o deleite, sem um uso prático propriamente. Essa terminologia, como vimos, foi retomada durante a Idade Média, que nada mais fez do que dar continuidade à classificação que era feita no mundo grego antigo.

Outro aspecto importante a se destacar desde já é que algumas dessas artes ditas recreativas eram voltadas basicamente para dois sentidos do homem: a visão e a audição, sendo desprezados todos os outros sentidos. Do mesmo modo, essa divisão serviu também para englobar as artes que, de acordo com Cícero, contemplam a realidade com a alma e as artes que simplesmente fazem ou empreendem algo. Por ter essa "contemplação" da realidade com a alma, a visão adquire, desde já, um sentido de percepção mais nobre, mais elevado, algo que será valorizado por quase todos os filósofos antigos e medievais, pois éa partir do sentido da visão, na contemplação de uma pintura por exemplo, que se reconhecerão os as virtudes e os vícios dos homens.

Aqui é feita uma distinção entre as artes que servem para esse deleite, como pintar, modelar e cantar, em oposição às artes que têm uma necessidade útil ou prática, como a agricultura e a arquitetura, embora sejam, todas elas, perceptíveis pelos sentidos, mas nem todas com o mesmo grau de valorização. Além desta divisão, o filósofo Cícero também fez uma divisão das artes em artes grandes (artes maximae), como as artes militares e bélicas; média (artes mediocres), que são as artes intelectuais, voltadas para a ciência, mas também a poesia e a eloquência; e menores (artes minores), como a pintura, a escultura, a música, a 'atuação' e o atletismo. A partir daqui, as artes vão passar a ter a rotulação de artes liberais e artes vulgares.

Até aqui, temos esses dois tipos de artes: as vulgares e as liberais. Platão fez também uma classificação, embora sem muito destaque no que se refere a modificações do que já estava em voga até o momento, de maneira que temos dois tipos de artes em Platão: as produtivas e as imitativas. No entanto, desde essa época, já há uma valorização da poesia, uma vez que há a inspiração direta das musas, que eram as entidades a quem se atribuíam a capacidade de inspirar as criações científicas ou artísticas dentro da mitologia grega, e esse é o entendimento oriundo de texto clássicos como os atribuídos a Homero.

Platão dá certo enfoque às artes que são voltadas para os dois principais sentidos humanos, aqueles que têm a capacidade de apreensão do fazer artístico, que são a visão e a audição, de maneira que, para este filósofo, temos as artes divinas e as artes humanas, ou as artes da produção (a partir do trabalho fabricado) e artes da aquisição (que tem a forma de disciplina, ou seja, nada fabricam). A poesia assume um caráter divino, pois falava diretamente aos deuses, e dos deuses para o homem. Nesse falar dos deuses e das musas, o que prevalecia era a inspiração do poeta. Quanto à arquitetura, ele a categoriza não como uma arte, mas sim como um ofício, inserida dentro do conhecimento de outras ciências e, por não ter esse caráter de elevação, de "conversa" com os deuses e as musas, ela é mais uma manufatura, como a tecelagem, do que uma arte que eleve às virtudes humanas.

Por sua vez, Aristóteles trata mais do fazer literário do que das artes propriamente ditas, enfocando a classificação das artes miméticas e privilegiando a dimensão do o trágico como a maior dentre elas. Ainda assim, há uma divisão das artes em Aristóteles, quando ele divide os fazeres (entendendo-se aqui as "técnicas", as artes) em dois tipos, as que usam a matéria e as que comandam. Além disso, as artes são classificadas em função da imitação da natureza e da complementação da natureza. No entanto, a arquitetura ficava de fora da classificação das artes, pois não era considerada uma "bela arte", como o 
eram a poesia, a música, a dança, a pintura. Ainda, Aristóteles, assim como Platão, distingue as artes de necessidade e as artes do prazer, que serão a base para a classificação das chamadas "belas-artes" num momento posterior. Além do mais, como em outros filósofos, há de se destacar a condição privilegiada que o sentido da visão tem em Aristóteles, como o sentido por excelência e por meio do qual se é possível a iluminação, o conhecimento e, por consequência, a imaginação.

O que vemos nos filósofos posteriores a Platão e Aristóteles é basicamente uma continuação da classificação que se viu até aqui, ainda ressaltando, juntamente com os posicionamentos filosóficos para a arte, a situação em que os sentidos corpóreos são enfatizados para a compreensão das artes, bem como para suas classificações e apreensões.

A poesia continua a ter um caráter elevado, com um objetivo de elevar o espírito no ouvinte, pois os poemas conduzem ao espírito, como visto no texto de Horácio. Embora este dê à audição um caráter mais elevado do que a visão, justamente instigam mais o ouvido do que a vista. E isso também ocorre porque as artes, sobretudo as artes liberais, ou seja, as artes dos homens livres, servirão para destacar o caráter da virtude humana, como apontou Sêneca.

Ou ainda para Plutarco, em que as artes serão correlacionadas com os sentidos e estarão ligadas à razão, posto que as diferenças se dão a partir da finalidade do que é julgado ou discernido. Dessa forma, para Plutarco, dando continuidade ao pensamento vigente até então, sobretudo de Platão e Aristóteles, a poesia, que está diretamente relacionada com a música, chega ao poeta por meio da inspiração e de um entusiasmo profético, um delírio causado pelos deuses, e o poeta era também associado a um adivinho, resgatando o sentido ea função que este tinha em povos antigos.

Destarte, ainda continuamos com as artes teóricas e as artes práticas, sobretudo as artes mais importantes com voltas à contemplação dos olhos. É o que aparece na classificação de Quintiliano, ao dividir as artes em três grupos, a saber: (1) as que constituem de estudo, conhecimento e apreciação das coisas (inspectio, cognitio, et rerum aestimatis), e as que não necessitam de qualquer tipo de atividade física do artista (chamados "teóricos" das artes); (2) as que se preocupam com a ação (actus) do artista (as artes práticas, como a dança, que têm um fim em si mesmas); e (3) as que produzem objetos, (effectus), e mantém a existência após a criação do artista ("poiética", com o sentido da palavra grega "poiein", produzir). Igualmente, são distinguidos três elementos nas artes: o conhecimento do artista, a sua ação e o produto da sua ação.

Outro nome de reforço nessa classificação de artes liberais e vulgares é Galeno, a partir das três ordens: as puramente teóricas, as artes figurativas e construtivas e as artes manuais. Além disso, há ainda a divisão das artes, para Galeno, em duas categorias: as artes intelectuais e respeitáveis e as insignificantes. No primeiro grupo, então, estão a medicina, a retórica e a música, a geometria, a aritmética, a lógica e a astronomia, a gramática e a jurisprudência (as artes voltadas para o homem livre, como vimos na classificação de Cícero), de maneira que temos as artes que produzem produtos artificias, como a arquitetura, e as artes que dão assistência aos seres naturais, como a medicina, a agricultura.

Esse reforço vai ganhar eco numa das mais completas classificações das artes herdadas dos tempos antigos, que é a classificação de Plotino, ao dividir as artes que produzem objetos físicos, como é o caso da arquitetura; as que ajudam a natureza, como a medicina e a agricultura. Além destas, há as que imitam a natureza, como a pintura; as que melhoram ou ornamentam a ação humana, como a retórica, a política e as artes militares, e as artes que são puramente intelectuais, como a geometria.

É justamente em Plotino que temos, de maneira clara, até o momento, o reforço da hierarquia das artes tendo por base o que ele considera como o grau de espiritualização delas, sendo a arquitetura a menos intelectual e espiritual, e a geometria a que apresenta - grau mais elevado de intelectualidade e espiritualidade. Então, temos a divisão das artes naquelas que melhoram a natureza, as artes produtivas, as que inserem a beleza na ação humana, as artes imitativas, e as artes mentais, formando, assim, uma hierarquia, partindo do mais material, mundano e imanente até a arte mais espiritual. Curiosamente, Plotino coloca a arquitetura num lugar muito alto pelo valor ontológico que a identifica com a própria beleza.

Marcas da distinção da arte em liberais e vulgares também são encontradas em Agostinho, quando, em seu tempo, as artes liberais já formavam a base do sistema educacional, além, também, de as artes ainda carregarem a acepção de uma habilidade a ser aprendida e desenvolvida, como uma técnica. 
Desse período pós-aristotélico, e antes de se chegar à Idade Média, há de se destacar a posição de Longino, cuja concepção das artes afasta-se da de Aristóteles, embora ainda se mantenha uma soberania da arte literária sobre as artes visuais.

Na Idade Média, por seu turno, há o predomínio das artes classificadas em função das artes liberais, o Trivium e o Quadrivium, período este que recebe esse sistema na forma das ciências lógicas (trivium) e das físicas e matemáticas (quadrivium), bem como o acréscimo das ciências mecânicas, mesmo com a prevalência da tradição dessas artes liberais, que se mantiveram em todo esse período. Além do que, embora o ensino fosse já relevante nesse tempo, o que era ensinado nas escolas não refletia o fazer artístico, fosse de obras elevadas ou práticas, voltadas para usos práticos.

Cassiodoro é o relevante nesse momento pelo caráter didático que sua obra apresenta em relação às artes, notadamente as artes liberais, criando um completo manual sobre a exposição dessas artes e tendo um papel fundamental na história e na cultura da Europa ocidental. Do mesmo modo, a partir da divisão que era feita dos trabalhos nesse período, as chamadas artes mecânicas se desenvolveram, tendo grande ênfase no registro dessa abordagem o filósofo Hugo de São Vitor, que divide as artes liberais a partir da matemática e da lógica, de maneira que as sete ciências mecânicas feitas na divisão de São Vitor adquirirão uma posição relevante na história pela primeira vez, e também fizeram deste filósofo o primeiro a formular a divisão das sete artes mecânicas em correspondência às sete artes liberais, enfatizando o fato de que algumas artes vão depender de um esforço físico e outras não, assim como faziam os gregos.

Além da prevalência das artes liberais, que passaram a ter um caráter normativo até o final do século XII, as artes mecânicas, de São Vitor, foram se modificando e a arquitetura, a que mais nos interessa aqui, ela colocada ao lado de outros ofícios, numa divisão da Armatura, tendo um lugar menor entre as artes mecânicas.

Por fim, Tomás de Aquino reforça essa divisão das artes ao mostrar duas classes de conhecimento: uma natural, pela qual se conhecem as coisas, e outra que vem da palavra, as coisas na palavra. Ele dá um caráter artístico às artes liberais, situando-as entre as ciências teóricas e as artes mecânicas, porque ela sugerem, além de um conhecimento, um processo da razão.
As divisão das sete artes permaneceram na Idade Média, sobretudo a partir do século IX, quando Boécio fez a separação das artes do trivium (três vias) e as artes do quadrivium (quatro vias). As artes do trivium foram mais aprofundadas do que as do quadrivium, principalemente a gramática, fundante de todas as outras, de acordo com Curtius. Com o surgimento das universidades, o sistema de ensino mudou, as artes perdem a pretensão de se voltarem para ensino da filosofia e se dissipam nas chamadas ciências profanas.

A partir de então, com o sistema de ensino preponderante nas universidades, primeiro em Paris e posteriormente na Alemanha, o ensino das artes passa a ter um caráter teórico, sendo fonte e foco de estudos dentro das universidades. Kant, Hegel e Schopenhauer foram professores que ensinaram algo desses aspectos da arte em suas aulas, tendo mais destaque, em relação a isso, notadamente Hegel e Schopenhauer, uma vez que Kant enfatiza mais a abordagem da Estética do que das artes de maneira mais específica.

Em um sentido moderno, as belas-artes são divididas em sete categorias: Música, Pintura, Escultura, Arquitetura, Literatura, Coreografia e Cinema. O conceito de belas artes é associado à ideia de que um certo conjunto de suportes e manifestações artísticas é superior aos demais. Até o século XIX, as escolas de arte classificavam-nas em basicamente dois tipos: as belas artes e as artes aplicadas ou artes secundárias. As belas artes eram aquelas que, segundo o ponto de vista do período, possuíam a diginidade da nobreza. Já as artes aplicadas, devido ao fato de serem praticadas por trabalhadores, eram desvalorizadas. Assim, compunham as belas artes a pintura, a escultura e o desenho, todas elas subordinadas à arquitetura.

Em geral, o termo arte, ou belas-artes, é entendido apenas como artes visuais, embora possua acepção mais ampla, compreendendo as cinco principais artes: pintura, escultura, arquitetura, música e poesia. Algumas outras artes são adicionadas às vezes a este grupo, com menor regularidade, como a jardinagem, a gravura, as artes decorativas, a dança, o teatro, a ópera. É dado como certa que a distinção das cinco grandes artes como uma área comum entre si, distinta de outras atividades científicas humanas, bem como do artesanato, começou a ser notada com mais atenção principalmente a partir de Kant. Esse sistema das cinco principais artes assumiu a forma que conhecemos hoje a partir do século XVIII, ainda que 
muitos dos elementos se refiram à expressão do pensamento da antiguidade, da época medieval e renascentista.

As artes, em Immanuel Kant, diferenciam-se de outras habilidades a partir de três características: como produção, a arte diferencia-se da natureza, que é ação, assim como o agir, bem como o "opus" (obra) diferencia-se do "effecctus" (efeito), e se realizam mediante a liberdade. Ainda, para o filósofo, as artes distinguem-se do ofício, pois é uma "arte remunerada", enquanto aquela é uma "arte livre", portanto, a arte é diferente do artesanato porque este produz uma intenção, e também diferente das artes mecânicas, que realizam uma intenção. Ao propora classificação das "belas-artes" em artes da palavra (eloquência e poesia), figurativas (escultura, arquitetura e pintura), e tomar como critério para tal divisão a comparação das artes com os meios de expressão que servem ao homem para se comunicarem, ele faz uma classificação sem levar em conta, necessariamente, uma hierarquia. A arte, para Kant, "a bela arte", tem que ser arte livre, sendo que, em função disso, ele a divide em três espécies: as elocutivas, as figurativas e a arte do jogo das sensações. O sistema elaborado por Kant para as artes estabelece as relações entre as artes que fazem parte de um mesmo grupo a partir de características próprias.

Quanto aos sentidos, há, para Kant, dois tipos: externo e interno. O sentido interno, o que ele chama de faculdade da percepção ou da intuição empírica, difere-se do sentimento de prazer e desprazer. Esse sentido interno é a faculdade das nossas representações dos objetos em nossos pensamentos.

Quanto à hierarquia a poesia ocupa a posição mais alta, a qual deve ao gênio, quase totalmente, a sua, $e$ também é a que "menos quer ser guiada por prescrição ou exemplos”. A poesia, assim, eleva-se esteticamente às ideias. Na poesia, tudo se passa "honrada e lealmente", e ela estimula um simples jogo de entretimento com a faculdade da imaginação. Assim, para Kant, a poesia ocupa o primeiro lugar, está acima das demais artes, e deve sua origem quase que inteiramente ao gênio.

Fazemos então a seguinte pergunta, para entender a posição da arquitetura em Kant: é possível encaixar/alocar a arquitetura, em Kant, num grau baixo das artes? Kant em seus questionamentos sobre a arte está mais voltado para o belo no âmbito estético e teleológico.
A arquitetura é a "arte de apresentar conceitos de coisas que somente são possíveis pela arte, e Kant a coloca deslocada das principais artes, em função do caráter utilitário que ela apresenta, mas se aproxima das demais artes pelos conceitos de beleza próprios dela, bem como a partir também de seus materiaise funções. Pela distinção que é feita entre a arte e o artesanato ou ofício, as formas básicas da arquitetura e da escultura são idênticas: a escultura aspira à monumentalidade e a arquitetura aspira à significação simbólica, fazendo uso, as duas, do mesmo material: a pedra, dotando-a de idênticos valores práticos, tanto na arquitetura quanto na escultura.

Por ter um objetivo ou mesmo uma finalidade prática, a finalidade da arquitetura é a construção. Ela assume uma postura prática em relação ao objeto artístico que se configura com a conclusão da obra arquitetônica. Há um propósito externo, que é o utilitário, e também um propósito interno, a configuração da obra acabada, não satisfaz a sua finalidade funcional, ela perde a característica de perfeição, ou seja, quanto mais funcional, mais perfeita ela será, e tanto mais útil também, criando, assim, uma adequação funcional à obra arquitetônica. O problema da arquitetura está condicionado ao uso que se faz da obra, sendo o caráter estético secundário. Ela só será "artística" na medida em que tiver um caráter simbólico associado a ela.

Na classificação e hierarquia, Kant situa a poesia como a arte mais elevada por ser uma arte voltada para o espírito. A importância à poesia se dá a partir da relação que a poesia passa a ter com o conhecimento, intensificando o pensamento a partir dos jogos das sensações. Ela está numa posição elevada, para o filósofo, porque há uma relação clara entre o belo e o sublime, culminando, a partir de um movimento de interiorização das artes, na poesia.

A divisão que Hegel faz das artes faz referência à classificação das artes particulares e das espécies artísticas particulares. Ele as divide quanto ao conteúdo, à apreensão e à exposição, apresentados na sua clássica divisão das formas de arte simbólica, clássica e romântica.

Hegel divide a sua estética em três partes: a primeira estuda o ideal em si, a ideia do belo na arte; a segunda estuda o 'sistema' das formas particulares, da maneira como se realiza na história: a simbólica, a clássica e a romântica. A última escala é o sistema das artes particulares, que classifica o grau de expressão do ideal: à arquitetura correspondente a arte simbólica; 
à escultura, a clássica e a pintura, a música e a poesia são integrantes das artes românticas. A subdivisão há de ser conforme a ideia internamente da obra de arte como tal, sendo que a primeira arte é a arquitetura, a segunda arte aparece como ideal, é a escultura, e a terceira é o subjetivo, a particularização: a pintura. A arte da fala, a poesia em geral, é "a arte absoluta, verdadeira", sendo ela o campo mais rico, incomensurável.

Hegel desenvolve a hierarquia das artes como uma modalidade espiritual, essa divisão se dará também por meio de uma hierarquia voltada à espiritualidade. A poesia é a arte universal para Hegel, ela parte do elemento mais sensível, em oposição à matéria pesada, como a arquitetura. No interior da hierarquia, a poesia assume uma posição distinta no esquema das artes, pois, quanto mais afastada do sensível, e próxima da espiritualização, a poesia assume, nessa hierarquia, o nível mais alto, tendo a sua manifestação de existência na consciência, ao contrário das obras de arte que representam na intuição as de formas inferiores, como a arquitetura. É por isso que a arquitetura é contraponto extremo à poesia, pois quase não se manifesta espiritualmente, quase não é espírito. Assim, na poesia, aquilo que é trazido na aparição da imaginação é algo que aparece sensivelmente.

Para Hegel, a arquitetura é, como a arte da construção, o início da arte em geral. A arquitetura constitui o início da arte, pois é a primeira a dar forma ao inorgânico, sendo anterior à escultura e à pintura.

$\mathrm{Na}$ arquitetura simbólica (a primeira arte historicamente), tem-se o que produz uma necessidade para a arte, um tipo de arquitetura autônoma, um fim em si mesma, por isso ela é simbólica. Dessa forma, esse tipo de arquitetura deve ter um sentido para o espírito por ser uma obra realizada por homens e, por isso, uma finalidade superior. Na arquitetura clássica, diferentemente da simbólica, ela é abstrata e serve fundamentalmente para um fim, cujo tipo de representação principal é o templo, ou seja, a arquitetura religiosa. Arquitetura romântica, à qual pertence a gótica, é a arquitetura propriamente cristã, pois tem-se, como fundamento, a casa fechada totalmente, excluindo o espírito do homem, recorrendo-se o seu ânimo para a devoção e afastando-se do mundo exterior. Uma vez que, para Hegel, a arte é a expressão do sensível e do divino, bem como a expressão da liberdade humana, ela deve representar o que é livre em oposição ao que não é livre, aquilo que apresenta resistência em relação à gravidade, a matéria inorgânica, representado, em relação à arte, sobretudo por meio da arquitetura.

Como a arquitetura transforma algo artificial em algo que é fruto da expressão do entendimento humano e da liberdade espiritual do homem. Ela só tem uma finalidade quando se criam templos, por isso Hegel só se preocupa nas formas de arquitetura enquanto expressões de arte, e não como construções distintas daquelas que ele enquadra nas três formas de arte arquitetônica - simbólica, clássica e romântica. Dessa forma, a arquitetura não ambiciona uma arte genuína porque não é expressão direta da liberdade do espírito. Além do mais, a arquitetura tem uma limitação porque ela expressa significados que não são claramente determinados, pois quase sempre é feita em função de uma utilidade, separando-a da pretensão de expressar a liberdade do espírito, e só reconhecemos a arquitetura como forma artística em função do seu caráter prático e cotidiano.

Hegel considera a arquitetura como a arte não espiritual, configurada a partir da leis da gravidade, associando a matéria à limitação daquilo que é construído. Dessa forma, para o filósofo, a arquitetura é a arte mais primitiva, a mais limitada justamente porque está associada à matéria, e não percebe a carga espiritual que o objeto carrega.

A poesia é a arte mais perfeita para Hegel, a primeira, pois é atribuída à comunidade, ao ânimo e ao sujeito. A poesia remete à interioridade que está unificada com o espírito de maneira imediata. Ela corresponde ao reino da representação, sendo o seu elemento o mais rico, pois tem a liberdade de difundir-se pelo todo particular, sendo o seu conteúdo o espiritual em sua "determinidade", torna-se uma figura livre, um todo, com independência ou determinado com um desejo e com uma vontade.

A poesia não tem uma precisão, ao contrário da pintura, que representa o momento, mesmo que com grande precisão. Para Hegel, a poesia é a forma mais perfeita de arte, porque ela expressa o espírito na sua idealidade mais completa, e não a realização do ideal da beleza com a conformidade entre o sensível e o espiritual. Seu material não aparece sensivelmente, mas é trazido na aparição da imaginação. Para o filósofo, a poesia é a arte universal porque não se realiza por meio de nenhum material, e sim por suas condições imateriais de se manifestar. Ela se afasta da forma de sensibilidade espiritualizada para se tornar arbítrio. Dessa forma, a poesia se torna, para Hegel, a arte espiritual por excelência. Ela está mais próxima 
da essência do espírito e da própria essência da arte, a vontade, a vida e o sentimento, sendo a forma mais eloquente da essência da arte, e é a arte cuja sensibilidade desaparece para dar lugar à espiritualidade. Além disso, a poesia também representa a Ideia e a Ideia do divino, a passagem da esfera superior do espírito.

De maneira que essa posição ocupada pela poesia, na hierarquia de Hegel, está na posição mais elevada porque ela tem esse caráter de aspirar a manifestação do espírito e o desprendimento dos elementos materiais, como no caso da arquitetura e da escultura por exemplo, por expressar também o espírito livre.

Schopenhauer apresenta sua classificação das artes seguindo um único critério: os graus de objetivação da vontade. A partir de um esforço de compreender a natureza das coisas, da vida e da existência, pode-se entender também que as belas artes possibilitam solucionar o problema da existência, pois ativa-se, em cada espírito, uma entrega à contemplação objetiva do mundo. A ideia da arte é a de que ela facilita o conhecimento das Ideias para o filósofo, e essa Ideia é a única via de intuição pela qual se tem o conhecimento de algo. Esta comunicação vai se dar, para ele, por meio da arte.

Schopenhauer identifica três princípios a fim de que se estabeleça uma hierarquia das artes. O primeiro é da objetivação da contemplação, cujas ideias das forças naturais correspondem à arquitetura. $O$ segundo princípio, como meio de hierarquizar as artes, é o da "impressão estética", a classificação que se dá conforme a objetividade crescente dada ao prazer estético. Um terceiro princípio é dado pela manifestação de tendência e a luta das forças contrárias. As artes, de acordo com Schopenhauer, têm em comum o fato de que elas se baseiam no princípio de que a arte se objetiva na Ideia.

Para o filósofo, o fim de todas as artes é somente um, o da apresentação da ideia. A diferença vai se dar nos graus de objetivação em que a vontade é apresentada, determinando o material da apresentação. Dessa forma, as artes mais distanciadas entre si permitem esclarecimento recíproco por comparações, assim, o que é realizado pelo arquiteto, a partir da matéria rígida, é o mesmo que faz o poeta com a ideia da humanidade.

A arquitetura e a hidráulica são, para Schopenhauer, os graus mais baixos da objetividade da Vontade, de maneira que os temas estéticos são Ideias no patamar mais baixo dessa objetivação.

A classificação feita por Schopenhauer das artes coloca a arquitetura na posição mais baixa, em função dos graus de objetivação da vontade. A arquitetura, pela sua materialidade e necessidade a uma obediência de uma necessidade, além da sua função prática, a impede de ter uma função estética verdadeira.

As artes, para Schopenhauer, traduzem as ideias da forma como elas se manifestam nos graus da escala dos seres. A arquitetura como arte representa os graus mais inferiores da objetividade da vontade. Assim, para Schopenhauer, na "bela arquitetura" há uma luta entre resistência e carga, suporte e carga, ou sustentação e peso. A massa, o peso, a carga e a resistência é o que mantêm, numa edificação bela de obra arquitetônica, e o seu equilíbrio, conciliando forças contrárias e transformando em harmonia essa oposição e a tornando visível aos olhos.

A arquitetura é tratada por Schopenhauer somente com fins estéticos, pois ele não a subordina, em suas considerações, à utilidade que é dada a ela ou a algo que seja estranho à questão da arte. Assim, o mérito do arquiteto é fazer com que a obra atinja fins estéticos mesmo levanto em consideração o fato de ela estar sujeitada a uma utilidade. E o que é captado numa obra arquitetônica são as forças fundamentais da natureza, o que ele chama de Ideias primeiras, os graus mais baixos da objetividade da Vontade. Por isso, na arquitetura, Schopenhauer vê uma luta entre e a Ideia e o fenômeno, ou entre a eternidade e o tempo. Que refletem numa hierarquia de Ideias das belas-artes. $\mathrm{E}$ nessa hierarquia, o que prevalece é a Ideia, e não o material empregado. A arquitetura, por estar relacionada com as qualidades da matéria, ela traduz essa luta entre a resistência e a carga.

Como pode, para o filósofo, a arquitetura ser uma bela arte a partir do seu fim estético específico? E a resposta é a situação de a arquitetura trazer para a mais clara intuição os graus mais baixos da objetividade da Vontade que ela representa. Nesse grau mais baixo se vê a luta entre a gravidade e a resistência, que é o único tema belo da arquitetura. A arquitetura só pode ter uma contemplação estética se se conhecer o material e os elementos que a constitui, o elementos de peso, rigidez e coesão, somente dessa forma pode-se falar em belo na arquitetura, de acordo com Schopenhauer. Mas o problema reside, sobretudo, na situação de a obra arquitetônica ter uma finalidade prática e, ao mesmo tempo, uma fruição estética e ser bela. Por isso o filósofo coloca a arquitetura no nível mais baixo da 
hierarquia das artes, porque ela tem o a objetivação da vontade no grau mais baixo e inferior de visibilidade, mostrando um impulso antagônico da disputa entre a gravidade e a rigidez.

Para o filósofo, a única matéria da arquitetura é a luta entre a gravidade (força) e rigidez. Em oposição, encontra-se na "série das belas artes", está o drama (uma das categorias da poesia), pois este conduz ao conhecimento das mais importantes ideias.

Nessa teoria das belas-artes de Schopenhauer, a poesia - ou as artes poéticas -, assim como as artes plásticas, têm o objetivo de manifestar as Ideias, que são os graus de objetivação da vontade. Essas Ideias são intuitivas, e, na poesia, a comunicação feita por palavras é somente o conceito abstrato. Dessa forma, a poesia tem em seu domínio a vantagem de comunicar Ideias em função da universalidade do material de que dispõe. Opera os meios de que a linguagem possibilita para atingir na mente do leitor a Ideia, o que confere na poesia o lugar do gênio para Schopehauer. Por tornar ao leitor uma ideia inteligível em função da objetividade que the confere a linguagem. Dessa forma, a poesia tem o poder de mover a imaginação por meio das palavras.

Não há outra obra que não a poesia para conseguir realizar a manifestação da Ideia, e esta corresponde ao grau mais elevado da objetividade da Vontade, como dito anteriormente, e a poesia é a única que consegue comunicar as Ideias de maneira universal, com esse caráter de universalidade e com um imenso domínio de extensão. O objetivo da poesia, então, é elevar ao grau mais alto da objetividade da Vontade a sua manifestação. Ela serve para a comunicação da Ideia, feita também pelas ações do homem, e são acompanhadas por pensamentos e afetos.

LLORENTE Marta. In RODRÍGUEZ Carmen (Edición): Introducción a la arquitectura: Conceptos fundamentales, 2000, p. 87. Disponivel em: https://dyaunet.files.wordpress.c om/2016/07/g-

introduccic3b3nalaarquitecturaco nceptosfundamentales.pdf. Acesso em: 17 mar 2015. é relegada ao nível mais baixo nos sistemas de hierarquia das artes, tanto de Hegel quanto de Schopenhuaer e de Kant, pois, para este, tem um fim necessário à sua conformidade.

As arquiteturas, com os aspectos gerais comuns às outras artes, apresentam conceitos próprios de beleza. A arquitetura, como estética de uma arte específica, é determinada pelo que lhe é peculiar, ou seja, seus materiais e funções. A estética moderna estabeleceu uma distinção categórica entre a arte e o artesanato ou ofício. Em seu início, as formas básicas da arquitetura e da escultura são idênticas, ou seja, na medida em que a escultura aspira à monumentalidade, e na medida em que a arquitetura aspira à significação simbólica e durabilidade, as duas artes fazem uso comum do mesmo material: a pedra, dotando-a de idênticos valores práticos.

Não podemos esquecer, contudo, a persistência da arquitetura, desde o início dos questionamentos de classificação a partir do século XVIII, em manter-se evidente dentro do âmbito das artes e a sua permanência como problema sendo reiteradamente recuperado. Como escreveu Marta Llorente:

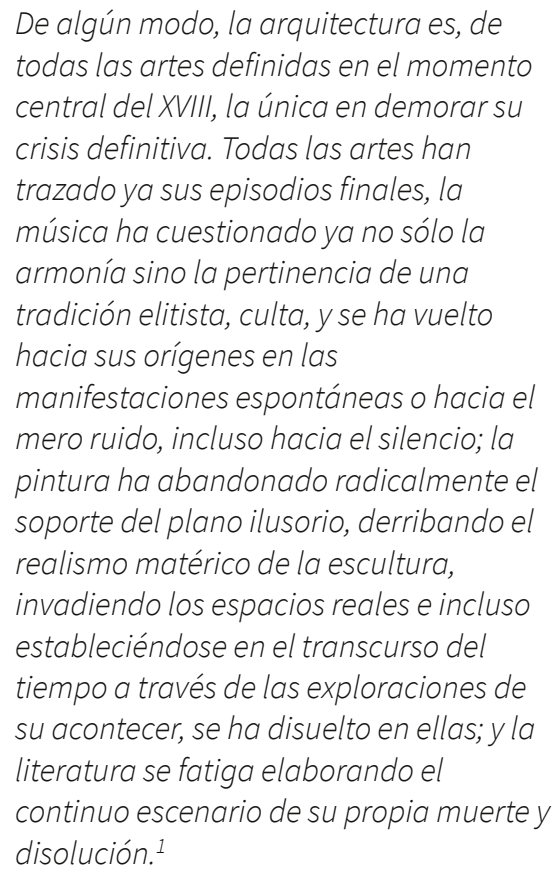

A arquitetura, ao elaborar os seus princípios estéticos, torna-se, ao lado da música, uma das artes mais particulares, pois expressa a sua necessidade de forma, por meio da geometria, em substituição aos critérios das demais artes plásticas. Além disso, está também muito próxima dos pressupostos científicos, ao tratar dos meios funcionais de utilização, por isso
A comparação das artes torna-se problemática quando se deixa de fora do sistema os elementos rigorosos que as caracterizam, por isso a comparação de artes quase opostas, do ponto de vista funcional e prático, como a poesia e a arquitetura, adquire mais uma conotação de embate do que uma reciprocidade entre elas. Notamos, dessa forma, que a hierarquia 
das artes vai sempre implicar numa posição privilegiada de uma em detrimento de outra, como se houvesse, dessa forma, uma arte que fosse "mais arte" do que outra.

As obras de destacam pelo que elas apresentam em si mesmas, de forma que sempre tivemos um poema melhor, do ponto de vista estético, do que outro poema, mesmo que ambos pertençam à mesma categoria artística. Basta uma análise mais crítica para detectar tais diferenças.

Vimos que a poesia ocupa um lugar elevado na hierarquia das artes porque a poesia sempre esteve associada à elevação do pensamento representado pela palavra. Mas, do ponto de vista físico, ela é tão material quanto a arquitetura, que depende de elementos concretos para se "concretizar", assim como a poesia requer elementos também físicos (seja a voz, seja o suporte em que é manifestada).

Separar as artes a partir dos aspectos materiais e espirituais também não se sustenta, por indiciar uma separação dita metafísica, que acompanha a evolução do ser humano ao longo da sua trajetória existencial. Assim, a poesia, para muitos filósofos, como vimos, está associada sempre ao aspecto espiritual, ligados e associados também ao gênio, como se este recebesse uma "inspiração divina", sem entenderem que o arquiteto, ao conceber uma obra de arte arquitetônica, também obtém, de alguma maneira, essa 'inspiração', esse daimon, na qual se apresenta, ainda, uma distinção entre corpo e alma. Assim, Hegel se equivoca ao colocar a arquitetura na base de uma hierarquia das artes, como se esta fosse a mais degradada das artes e a mais material porque não há representação do espírito nas obras de artes arquitetônicas. Ele não levou em consideração, por exemplo, os significados simbólicos mais cruciais que cada uma delas representam. A poesia, para Hegel, é posta como arte soberana e universal, mas também se equivocou ao considerar os aspectos limitantes que ela apresenta, como questões regionais de língua e cultura, ao contrário de outras manifestações artísticas, como a música, a pintura, a escultura ou mesmo a dança, que não necessitam da linguagem verbal para se manifestarem e serem entendidas.

Começamos nosso questionamento a partir das considerações de Hegel em estabelecer uma hierarquia das artes, dentro de seu sistema, e tentamos mostrar que, não somente Hegel, mas Kant e Schopenhauer (além de muitos outros filósofos) mantém, em aspectos gerais, a mesma estrutura de hierarquia das artes porque eles retomam um princípio estabelecido há séculos, sendo superado, talvez, com o desenvolvimento de outras formas artísticas, como a fotografia a partir do século XIX, e, no século XX, com o cinema.

\section{Bibliografia}

ARISTÓTELES. Poética. $7^{\mathrm{a}}$ ed. Lisboa: Imprensa Nacional-Casa da Moeda, 2003.

A poética clássica. Aristóteles, Horácio,

Longino. São Paulo: Cultrix, 1997.

BERTACCHI, André Rodrigues. O Panegírico, de Isócrates: tradução e comentário. 2014. Dissertação (Mestrado em Letras Clássicas) - Faculdade de Filosofia, Letras e Ciências Humanas, Universidade de São Paulo, São Paulo, 2014. doi:10.11606/D.8.2014.tde22052014-103653. Acesso em: 2017-03-16.

BAYER, Raymond. História da Estética. Lisboa: Editorial Estampa, 1995.

CURTIUS, E. R. Literatura Europeia e Idade Média latina. HUCITEC/Edusp, 1996

HEGEL, G. W. F. A Arquitetura. Tradução, introdução e notas de Oliver Tolle. São Paulo: Edusp, 2008.

. Filosofía del arte o Estética (verano de 1826). Apuntes de Friedrich Carl Hermann Victor Von Kehler. Universidade Autónoma de Madrid, Abada Editores, 2006.

Cursos de Estética IV. São Paulo: Edusp,

2004.

Lecciones sobre la estética. España:

Mestas, 2003.

Cursos de Estética I. A idéia do belo artístico. $2^{\circ}$ ed, São Paulo: Edusp, 2001.

Cursos de Estética II. O desenvolvimento do ideal nas formas do belo artístico. $2^{\circ}$ ed, São Paulo: Edusp, 2001.

Cursos de Estética III. O sistema das artes particulares. São Paulo: Edusp, 2001.

KANT, Immanuel. Crítica da Faculdade de Julgar. Tradução de Daniela Botelho B. Guedes. São Paulo: Editora Ícone, 2009. 
. Crítica da Faculdade do Juízo. Lisboa: Imprensa Nacional-Casa da Moeda, 1998.

Duas introduções à Crítica do Juízo. São

Paulo: Iluminuras, 1995.

PLATÃo. As leis. São Paulo: Edipro, 2010.

Sobre a inspiração poética (Íon) \& Sobre a mentira (Hípias Menor). Porto Alegre, RS: L\&PM, 2007.

. Critão, Menão, Hípias Maior e outros.

EDUFPA, 2007.

. Hípias Maior. Lisboa: Edições 70, 2000.

. Diálogos. O banquete. Fédon, Sofista,

Político. Editora Abril Cultural, 1972, pág. 27. Coleção Os Pensadores.

. A República. Introdução, tradução e notas de Maria Helena da Rocha Pereira. $9^{a}$ edição. Lisboa: Fundação Calouste Gulbenkian, s/d.

PLOTINO. Enéadas III-IV. Introducciones, traducciones y notas de Jesús Igal. Espanha: Editorial Gredos, 1985.

PLOTINO. Enéadas V-VI. ESapanha: Editorial Gredos, 1988.
PSEUDO-LONGINO. Do sublime. Tradução, Introdução e Comentário por Marta Isabel de Oliveira Várzeas. Imprensa da Universidade de Coimbra/ Annablume. 2015. Disponível em: hdl.handle.net/10316.2/38162

SCHOPENHAUER, Arthur. Parerga y Paralipomena. Madrid: Valdemar, 2009.

Fragmentos sobre a história da filosofia. São Paulo: Martins Fontes, 2007.

. Metafísica do belo. São Paulo: Editora UNESP, 2003.

Sobre a visão e as cores. São Paulo: Nova Alexandria, 2003.

. O mundo como vontade e representação. Rio de Janeiro: Contraponto, 2001.

SHINER, Larry. La invención del arte. Espanha: Paidos, 2004.

SOURIAU, E. A correspondência das artes: elementos de estética comparada. São Paulo: Cultrix/EDUSP, 1983. 